\title{
Capsule Commentary on Joynt et al., The Impact of Neighborhood Socioeconomic Status and Race on the Prescribing of Opioids in Emergency Departments Throughout the United States
}

\author{
Lorna Simon, MA \\ Center for Mental Health Services Research, University of Massachusetts Medical School, Worcester, MA, USA.
}

$\mathrm{J}$ Gen Intern Med 28(12):1647

DOI: $10.1007 / \mathrm{s} 11606-013-2547-5$

(c) Society of General Internal Medicine 2013

$\mathrm{T}$ his study used data from the National Hospital Ambulatory Medical Care Survey (NHAMCS) between 2006 and 2009 to examine the prescription of opioids for moderate to severe pain in emergency departments across the United States. ${ }^{1}$ Patients from poorer neighborhoods and African-Americans and Latinos were less likely to be prescribed opioids. The effects for race and ethnicity persisted even when neighborhood factors were controlled.

This study is the first to examine the effect of socioeconomic status (SES) on the prescription of opioids, and is thus an important addition to the literature on inequities in health care. As the authors note, however, the study is limited in that individual patient characteristics for SES were unavailable and neighborhood characteristics were used as proxies for patient SES.

Inequities in the delivery of health care for minority groups generally, ${ }^{2}$ and in the prescription of opioids specifically, ${ }^{3,4}$ has been well documented and reflect inequities in society as a whole. However, emergency department physicians typically see patients for a short period of time, and often have little personal knowledge about their patients. As a consequence, ED physicians may be more likely to make decisions about opiate prescriptions based on cultural stereotypes, specifically the perception that racial and ethnic minorities are more likely to abuse drugs of all sorts.

Health care is delivered in the context of a relationship between the provider and the patient, ${ }^{5}$ and many factors may influence prescribing practices, including how patients report their symptoms, how these reports are interpreted by clinicians and whether or not pain medications are requested. ${ }^{3}$ While likely an important component, current inequities in the quality of care delivered to minorities is unlikely to be determined by cultural stereotypes alone. ${ }^{3}$ Future research needs to move beyond documenting inequities. We need to determine the sources of these disparities and test interventions to reduce disparate care.

Conflict of Interest: The author declares no conflict of interest.

Corresponding Author: Lorna Simon, MA; Center for Mental Health Services Research, University of Massachusetts Medical School, Worcester, MA 01655, USA (e-mail: Lorna.simon@ umassmed.edu).

\section{REFERENCES}

1. Joynt M, Train MK, Robbins BW, Halterman JS, Caiola E, Fortuna RJ. The impact of neighborhood socioeconomic status and race on the prescribing of opioids in emergency departments throughout the United States. J Gen Intern Med. 2013. doi:10.1007/s11606-013-2516-z.

2. A Report on Racial and Ethnic Disparities in Health Care. http:// www.ama-assn.org/ama/pub/about-ama/our-people/member-groupssections/minority-affairs-section/news-resources/racialethnic-healthcare-disparities/report-racial-ethnic.page\#

3. Pletcher MJ, Kertesz SG, Kohn MA, Gonzales R. Trends in opioid prescribing by race/ethnicity for patients seeking care in US emergency departments. JAMA. 2008;299(1):70-78.

4. Todd KH, Deaton C, D'Adamo AP, Goe L. Ethnicity and analgesic practice. Ann Emerg Med. 2000;35(1):11-16.

5. Cooper LA, Beach MC, Johnson RL, Inui TS. Delving below the surface: understanding how race and ethnicity influence relationships in health care. J Gen Intern Med. 2006;21:S21-S27. 